\title{
Cardiovascular disease risk factors and anthropometry features among seemingly healthy young adults
}

\author{
Viskasari P. Kalanjati ${ }^{1}$, Rury T. Oktariza ${ }^{2}$, Bambang E. Suwito ${ }^{3}$, Krisnawan A. Pradana ${ }^{4}$, Dzanuar \\ Rahmawan $^{5}$, Abdurachman ${ }^{6}$ \\ ${ }^{1,6}$ Department of Anatomy and Histology, Faculty of Medicine, Universitas Airlangga, Indonesia \\ ${ }^{2,3,4,5}$ Faculty of Medicine, Universitas Airlangga, Indonesia
}

\begin{tabular}{l} 
Article Info \\
\hline Article history: \\
Received Jun 29, 2020 \\
Revised Dec 20, 2020 \\
Accepted Jan 4, 2021 \\
\hline
\end{tabular}

Keywords:

Body composition

Cardiovascular risks

Youth

\begin{abstract}
We explored association between the levels of total cholesterol (TC) and uric acid (UA) to the middle upper arm circumference (MUAC), waist circumference (WC) and hip circumference (HC) amongst seemingly healthy university students in Kediri, Indonesia aged 1723 years $(n=150)$; no history of major previous diseases were found (i.e. metabolic syndrome). TC and UA measured from the capillary blood; standardised anthropometry measurements were done by trained medical doctors. Correlation, linear regression, independent $\mathrm{t}$ test or Mann-Whitney analysis were performed with the level of significance of $p<0.05$. We found higher TC $(p=0.053)$, UA $(p<0.001)$, MUAC $(p=0.009), \mathrm{HC}(\mathrm{p}=0.865)$ and WC $(\mathrm{p}=0.001)$ among males than among females. TC was significantly correlated to the UA with prevalence of hypercholesterolemia of $46.7 \%$ and hyperuricemia of $30 \%$ of all participants. All anthropometry was significantly correlated to the TC and UA among males $(\mathrm{p}<0.001)$; TC and UA were strongly corresponded to all anthropometry parameters among males. Hypercholesterolemia and hyperuricemia could be found amongst the seemingly healthy young adults in Indonesia; among males these are strongly correlated to the higher MUAC, WC and HC. Daily physical activity and proper healthy diet might help to decrease these cardiovascular disease risk factors.
\end{abstract}

This is an open access article under the CC BY-SA license.

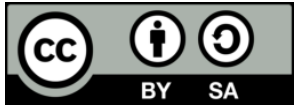

\section{Corresponding Author:}

Viskasari P. Kalanjati

Department of Anatomy and Histology

Faculty of Medicine

Universitas Airlangga, Surabaya, Indonesia

Email: viskasari-p-k@fk.unair.ac.id

\section{INTRODUCTION}

Cardiovascular diseases (CVDs) become a global epidemic and have been reported to be associated to the overweight and obesity [1-3]. Middle upper arm circumference (MUAC), waist circumference (WC) and hip circumference (HC) have been demonstrated as the efficient screening parameters for the assessment of obesity and overweight in various ethnic groups other than the body mass index (BMI) [4-6]. These parameters have been proposed to have good correlations to the corporal mass and fat distribution, and could detect nutritional status and several biomarker changes such as occur in the hypercholesterolemia and hyperuricemia [7-9]. Obesity and BMI z-scores were reported to correlate significantly to the occurance of 
metabolic syndrome, hyperuricemia and hypercholesterolemia although limited data have yet abundance amongst the seemingly healthy young adults [10-12]. In general population, the prevalence of hyperuricemia is approximately 20-25\%; whilst the prevalence of hypercholesterolemia (defined as total cholesterol or TC $\geq 5.0 \mathrm{mmol} / \mathrm{l}$ ) is approximately $37-40 \%[11,13,14]$. Previous studies have been focused on various age groups and clinical background [4-6], however, to the best of our knowledge, data from the seemingly healthy young males and females are still limited. These data are vital for preventive medicine of the cardiovascular diseases to develop in the later life [15-17]. Here we investigate the association between MUAC, WC and HC to the levels of TC and UA as these anthropometry features are proposed to be the indirect indicators to detect hypercholesterolemia and hyperuricemia as the risk factors of CVDs in the seemingly healthy male and female students (17-23 year old).

\section{RESEARCH METHOD}

The ethical clearance of this study was granted by the Ethical Committee no.179/HRECC.FODM/IV/2019. Each participant signed the informed consent and consent for information papers prior to the study. The participants were recruited from Kediri city, Indonesia (74 males and 76 females, respectively), age 17-23 year old, with no previous health problems i.e. metabolic syndrome, hypercholesterolemia and hyperuricemia. The TC (in $\mathrm{mg} / \mathrm{dL}$ ) and UA (in $\mathrm{mg} / \mathrm{dL}$ ) were analysed from the finger prick capillary blood-test using a stick machine (Easy Touch GCHb, Taiwan) without prior fasting. In this study, hypercholesterolemia was defined when the total cholesterol level was $\geq 200 \mathrm{mg} / \mathrm{dL}$; whilst hyperuricemia was defined if participants having their UA concentration was $>7.0 \mathrm{mg} / \mathrm{dL}(416.4 \mu \mathrm{mol} / \mathrm{L})$ among males or $>6.0 \mathrm{mg} / \mathrm{dL}(356.9 \mu \mathrm{mol} / \mathrm{L})$ among females $[11,13,14]$. These cut-off values were selected as they are generally used in clinical laboratories and have been proposed in previous studies in relation to metabolic syndrome and cardiovascular disease outcomes to define hypercholesterolemia and hyperuricemia $[11,18,19]$.

All anthropometric measurements were taken in accordance with World Health Organization (WHO) standards by two pre-trained medical doctors (technical personnels trained in research methods) [6, 14, 20]. All anthropometric measurements were taken twice and the average was recorded. If the measurements varied by more than $0.2 \mathrm{~cm}$, a third measurement was conducted. The average of the nearest two measures was recorded. The MUAC, WC and HC were measured in a standing position following standard procedures using calibrated instrument. MUAC was measured with a non-stretchable MUAC measuring tape at a point equidistant between the acromion process of the scapula and the olecranon process of the ulna. Waist circumference was measured midway between the lower rib margin and the iliac crest in the horizontal plane. Hip circumference was measured at the point yielding the maximum circumference over the buttocks using a tape measure $[5,15,21]$.

All data were analyzed using SPSS 17.0 (USA) and MaxStat Lite 3.06 (Germany). The KolmogorovSmirnov normality test and Bartlett homogeneity test of Bartlett were calculated prior to the independent t-test or Mann-Whitney test to analyze the difference of each variable among males and females. The Pearson or Spearman correlation tests were applied to seek correlations between the TC to WC, to HC and to MUAC in both male and female groups. Linear regression analysis between TC as the dependent variable and UA, MUAC, WC and $\mathrm{HC}$ as independent variables were conducted to seek the relationship in males and in females. Level of significance was considered when $\mathrm{p}<0.05$.

\section{RESULTS AND DISCUSSION}

Of 150 subjects, 76 female and 74 male students completed the study, accordingly. Table 1 shows a summary of their characteristics. The range of TC among males was $105-382 \mathrm{mg} / \mathrm{dL}$, whilst among female was $103-338 \mathrm{mg} / \mathrm{dL}$. Seventy participants had a hypercholesterolemia $(46.7 \%)$ and the rests were normal. Sixteen males and 14 females had hyperuricemia (30\%); whilst the rests were normal. The average and standard deviation of TC, WC, HC and MUAC are detailed in Table 1. The TC, MUAC and HC were homogeneous and normally distributed whilst the UA and WC were not thus we conducted the independent $\mathrm{t}$ test for the parametric and Mann-Whitney test for the non-parametric data as shown in Table 1. We observed higher values in TC, UA, MUAC, WC and $\mathrm{HC}$ of males compared to the females. There were significantly differences between the UA, MUAC and WC of males than females $(p<0.001, p=0.009, p=0.001$, respectively). However no significant differences were found between the TC and HC among males and females ( $\mathrm{p}=0.053$ and $\mathrm{p}=0.865$, respectively).

Among males, association between TC to the UA, MUAC, WC and $\mathrm{HC}$ was moderate with each beta value of $0.317,0.374,0.365$ and 0.367 , respectively; all of these had a significant coefficient of correlation $(\mathrm{p}<0.05)$. The proportion of variance in TC that can be explained by UA was $10.1 \%$; $14 \%$ by the MUAC; $13.4 \%$ by the WC and $13.5 \%$ by the HC. On the other hand, the proportion of variance in UA that

Int. J. Public Health Sci. Vol. 10, No. 1, March 2021: 77 - 82 
can be explained by TC was $10.1 \% ; 16 \%$ by the MUAC; $14.2 \%$ by the WC and $18.3 \%$ by the HC as shown in Table 2. There were positive significant correlations between TC to the UA, or MUAC, or WC, or HC among male students. The strongest correlation was shown between the $\mathrm{WC}$ and $\mathrm{HC}$ among males with $\mathrm{r}=0.926$ ( $\mathrm{p}<0.001)$; whilst the weakest correlation was shown between the TC and UA among males although the $\mathrm{r}$ was still showing moderate strength at $0.31(\mathrm{p}=0.007)$. Among females, association between $\mathrm{TC}$ to the $\mathrm{UA}$; and between UA to the $\mathrm{HC}$ was higher compared to the other variable associations with the beat value of 0.471 and 0.238 , respectively; all of these had a significant coefficient of correlation $(\mathrm{p}<0.05)$. The proportion of variance in TC that can be explained by UA was $22.2 \%$; whilst only $0.2 \%$ by the MUAC; $0.2 \%$ by the WC and $0.5 \%$ by the HC. On the other hand, the proportion of variance in UA that can be explained by TC was $22.2 \%$; whilst only $0.7 \%$ by the MUAC; $2.7 \%$ by the WC and $5.7 \%$ by the HC as shown in Table 3.

Table 1. Differences between TC, UA, MUAC, WC and HC of males to females

\begin{tabular}{clccc}
\hline No & Independent t-test (or Mann-Whitney test) & Male $(\mu \pm \mathrm{SD})$ & Female $(\mu \pm \mathrm{SD})$ & $\mathrm{p}$ \\
\hline 1 & Total Cholesterol in $\mathrm{mg} / \mathrm{dL}$ & $207.39 \pm 4.69$ & $193.68 \pm 40.28$ & 0.053 \\
2 & Serum of Uric Acid in $\mathrm{mg} / \mathrm{dL}$ & $5.95 \pm 1.78$ & $4.86 \pm 1.43$ & $<0.001^{*}$ \\
3 & MUAC in cm & $28.36 \pm 4.77$ & $26.45 \pm 3.97$ & $0.009^{*}$ \\
4 & Waist Circumference in cm & $82.1 \pm 1.6$ & $74.59 \pm 1.1$ & $0.001^{*}$ \\
5 & Hip Circumference in cm & $97.19 \pm 9.8$ & $96.93 \pm 8.71$ & 0.865 \\
& $\mathrm{n}$ & 74 & 76 & $*$ sig-2 tailed \\
\hline
\end{tabular}

Table 2. Association between TC and UA to the MUAC, WC and HC among males

\begin{tabular}{|c|c|c|c|c|c|c|}
\hline MALES & Linear regression test & & & lependent varia & & \\
\hline No & Dependent variable & $\mathrm{TC}$ & UA & MUAC & WC & $\mathrm{HC}$ \\
\hline 1 & $\mathrm{TC}$ & & $\begin{aligned} & \mathrm{R}^{2}=0.101 \\
& \text { Beta }= 0.317 \mathrm{p}=0.006^{*} \\
& \mathrm{~B}=8.124\end{aligned}$ & $\begin{array}{c}\mathrm{R}^{2}=0.14 \\
\text { Beta }=0.374 \\
\mathrm{p}=0.00^{*} \\
\mathrm{~B}=3.585\end{array}$ & $\begin{array}{c}\mathrm{R}^{2}=0.134 \\
\text { Beta }=0.365 \\
\mathrm{p}=0.001^{*} \\
\mathrm{~B}=1.209\end{array}$ & $\begin{array}{c}\mathrm{R}^{2}=0.135 \\
\text { Beta }=0.367 \\
\mathrm{p}=0.001^{*} \\
\mathrm{~B}=1.713\end{array}$ \\
\hline 2 & UA & $\begin{array}{c}\mathrm{R}^{2}=0.101 \\
\text { Beta }=0.317 \\
\mathrm{p}=0.006^{*} \\
\mathrm{~B}=0.012\end{array}$ & & $\begin{array}{l}\mathrm{R}^{2}=0.16 \\
\mathrm{Beta}=0.4 \\
\mathrm{p}<0.001^{*} \\
\mathrm{~B}=0.149\end{array}$ & $\begin{array}{c}\mathrm{R}^{2}=0.142 \\
\text { Beta }=0.377 \mathrm{p}=0.001 * \\
\mathrm{~B}=0.049\end{array}$ & $\begin{array}{c}\mathrm{R}^{2}=0.183 \\
\text { Beta }=0.428 \\
\mathrm{p}<0.001^{*} \\
\mathrm{~B}=0.078\end{array}$ \\
\hline \multicolumn{7}{|c|}{$\begin{array}{l}\text { Pearson (or Spearman) correlation test. } \\
* \text { is statistically significant. }\end{array}$} \\
\hline No & Variable & $\mathrm{TC}$ & UA & MUAC & WC & $\mathrm{HC}$ \\
\hline 1 & $\mathrm{TC}$ & & $\begin{array}{c}\mathrm{r}=0.31 \\
\mathrm{p}=0.007 *\end{array}$ & $\begin{array}{c}\mathrm{r}=0.374 \\
\mathrm{p}=0.001 *\end{array}$ & $\begin{array}{c}\mathrm{r}=0.349 \\
\mathrm{p}=0.002^{*}\end{array}$ & $\begin{array}{c}\mathrm{r}=0.367 \\
\mathrm{p}=0.001 *\end{array}$ \\
\hline 4 & WC & & & & & $\begin{array}{l}\mathrm{r}=0.926 \\
\mathrm{p}<0.001 *\end{array}$ \\
\hline 5 & $\mathrm{HC}$ & & & & & \\
\hline
\end{tabular}

Among females, there were positive significant correlations between TC to UA $(r=0.408, p<0.001)$; between UA to HC ( $r=0.245, \mathrm{p}=0.033)$; between MUAC to WC $(r=0.789, \mathrm{p}<0.001)$; between MUAC to HC $(\mathrm{r}=0.768, \mathrm{p}<0.001)$ and between $\mathrm{HC}$ to $\mathrm{WC}(\mathrm{r}=0.848, \mathrm{p}<0.001)$. The strongest correlation was shown between the WC and HC among females with $\mathrm{r}=0.848(\mathrm{p}<0.001)$; whilst the weakest correlation was shown between the TC and WC among females $(\mathrm{r}=0.065, \mathrm{p}=0.578)$. Reversed correlation was shown between TC and MUAC with $\mathrm{r}=-0.041$ ( $\mathrm{p}=0.727$ ). In our study, 1 point increase on the UA corresponded to 8.124 points increase on the TC; 1 point increase on the MUAC corresponded to 3.585 points increase on the TC; 1 point increase on the WC corresponded to 1.209 points increase on the TC; and 1 point increase on the HC corresponded to 1.713 points increase on the TC of males. Furthermore, among males, 1 point increase on the TC corresponded to 0.012 points increase on the UA; 1 point increase on the MUAC corresponded to 0.149 points increase on the UA; 1 point increase on the WC corresponded to 0.049 points increase on the UA; and 1 point increase on the $\mathrm{HC}$ corresponded to 0.078 points increase on the UA. On the other hand, among females, 1 point increase on the UA corresponded to 13.234 points increase on the TC; with 1 point increase on the MUAC corresponded to 0.413 points decrease on the TC; 1 point increase on the WC corresponded to 0.168 points increase on the TC; and 1 point increase on the $\mathrm{HC}$ corresponded to 0.343 points increase on the TC. Among females, 1 point increase on the TC corresponded to 0.017 points increase on the UA; 1 point increase on the MUAC corresponded to 0.031 points increase on the UA; 1 point increase on the WC 
corresponded to 0.024 points increase on the UA; and 1 point increase on the HC corresponded to 0.039 points increase on the UA.

Table 3. Association between TC and UA to the MUAC, WC and HC among females

\begin{tabular}{|c|c|c|c|c|c|c|}
\hline \multirow{2}{*}{$\begin{array}{c}\text { FEMALES } \\
\text { No } \\
\end{array}$} & \multirow{2}{*}{$\begin{array}{l}\text { Linear regression test } \\
\text { Dependent variable }\end{array}$} & \multirow[b]{2}{*}{ TC } & \multicolumn{2}{|c|}{ Independent variable } & \multirow[b]{2}{*}{ WC } & \multirow[b]{2}{*}{$\mathrm{HC}$} \\
\hline & & & UA & MUAC & & \\
\hline 2 & UA & $\begin{array}{c}\mathrm{R}^{2}=0.222 \\
\text { Beta }=0.471 \mathrm{p}<0.001 * \\
\mathrm{~B}=0.017\end{array}$ & $\begin{array}{c}\mathrm{R}^{2}=0.222 \\
\text { Beta }=0.471 \mathrm{p}<0.001 * \\
\mathrm{~B}=13.234\end{array}$ & $\begin{array}{c}\mathrm{R}^{2}=0.002 \\
\text { Beta }=-0.041 \\
\mathrm{p}=0.727 \\
\mathrm{~B}=-0.413 \\
\mathrm{R}^{2}=0.007 \\
\text { Beta }=0.085 \\
\mathrm{p}=0.466 \\
\mathrm{~B}=0.031\end{array}$ & $\begin{array}{c}\mathrm{R}^{2}=0.002 \\
\text { Beta }=0.04 \\
\mathrm{p}=0.732 \\
\mathrm{~B}=0.168 \\
\mathrm{R}^{2}=0.027 \\
\text { Beta }=0.163 \\
\mathrm{p}=0.16 \\
\mathrm{~B}=0.024\end{array}$ & $\begin{array}{c}\mathrm{R}^{2}=0.005 \\
\text { Beta }=0.074 \\
\mathrm{p}=0.525 \\
\mathrm{~B}=0.343 \\
\mathrm{R}^{2}=0.057 \\
\text { Beta }=0.238 \\
\mathrm{p}=0.038^{*} \\
\mathrm{~B}=0.039\end{array}$ \\
\hline \multicolumn{7}{|c|}{$\begin{array}{l}\text { Pearson (or Spearman) correlation test. } \\
* \text { is statistically significant. }\end{array}$} \\
\hline No & Variable & $\mathrm{TC}$ & UA & MUAC & WC & $\mathrm{HC}$ \\
\hline 1 & $\mathrm{TC}$ & & $\begin{array}{l}\mathrm{r}=0.408 \\
\mathrm{p}<0.001^{*}\end{array}$ & $\begin{array}{l}r=-0.041 \\
p=0.727\end{array}$ & $\begin{array}{l}\mathrm{r}=0.065 \\
\mathrm{p}=0.578\end{array}$ & $\begin{array}{l}\mathrm{r}=0.074 \\
\mathrm{p}=0.525\end{array}$ \\
\hline 2 & UA & & & $\begin{array}{l}\mathrm{r}=0.132 \\
\mathrm{p}=0.255\end{array}$ & $\begin{array}{l}\mathrm{r}=0.194 \\
\mathrm{p}=0.093\end{array}$ & $\begin{array}{c}\mathrm{r}=0.245 \\
\mathrm{p}=0.033^{*}\end{array}$ \\
\hline 3 & MUAC & & & & $\begin{array}{l}\mathrm{r}=0.789 \\
\mathrm{p}<0.001^{*}\end{array}$ & $\begin{array}{l}\mathrm{r}=0.768 \\
\mathrm{p}<0.001 *\end{array}$ \\
\hline 4 & WC & & & & & $\begin{array}{l}r=0.848 \\
\mathrm{p}<0.001 *\end{array}$ \\
\hline 5 & $\mathrm{HC}$ & & & & & \\
\hline
\end{tabular}

Here we observed higher MUAC, WC and HC among males compared to females. The anthropometric measures are the result of both genetic and environmental factors. The interaction between these factors could be explaining the differences within and between groups [22-24]. A pilot study conducted amongst 100 participants aged 17-60 year old in Singapore showed that the mean stature, weight, and body mass index were $173.2 \mathrm{~cm}, 69.5 \mathrm{~kg}$ and $23.2 \mathrm{~kg} / \mathrm{m}^{2}$ for males; whilst $161.1 \mathrm{~cm}, 56.8 \mathrm{~kg}$ and $21.9 \mathrm{~kg} / \mathrm{m}^{2}$ for females, respectively. They reported that males had larger body dimensions than females; differences between genders were about 0.7 to $17.4 \mathrm{~cm}$ [20]. In other study, it was reported that males have more lean mass, whilst females have more fat mass than males. Males are more likely to accumulate adipose tissue around the trunk and abdomen, whereas females generally accumulate adipose tissue around the hips and thighs [20-24]. Previous study showed that females have lower percentage of visceral adipose tissue and higher percentage of subcutaneous trunk abdominal adipose tissue than males. These sex-specific differences in body composition are associated with sex-based differences in energy substrate-utilization patterns; that is, females store more lipids and have higher whole-body insulin sensitivity than males, while men tend to oxidize more lipids than females. These patterns are influenced by the unique actions of sex hormones and adipokines in each sex as well as by nutritional status and physical fitness in both sexes [8, 9, 12].

We found the TC and UA of males were higher than these of females. Although, Zhu et al. reported that the total cholesterol levels were significantly higher among females than that of male group. However they also observed that the BMI, WC and waist to hip ratio were significantly associated to the CVD risk factors showed in the higher occurrence of dyslipidemia especially among females [25]. Here we also found that higher TC correlated significantly to the higher MUAC, WC and HC among males; a females however, higher TC was significantly correlated only to higher HC. It was reported that MUAC was correlated well to the BMI and could indicate the nutritional status amongst adults. The WC and $\mathrm{HC}$ have also been demonstrated to have a good association to the nutritional status and BMI [3, 8, 16]. A large hip circumference seems to convey strong and independent protection against development of CVD or early mortality in women. Hip size does not seem to be related to CVDs in men. However, it cannot be excluded entirely that wide hips may be protective against early total mortality in men. On the contrary, the waist circumference generally represents the abdominal or central obesity. This type of obesity would largely correlate to the higher risk of CVD amongst adults. The waist to hip ratio is widely studied in terms of its correlation to several metabolic diseases and the increased value commonly associated to the excess fat located in the upper abdominal region (visceral fat). If the waist circumference is higher than the hip circumference the apple shaped body is formed; whereas the waist circumference is lower than the hip circumference then this would be the pear shaped body. Males have been reported to have apple shaped body than females, and vice versa. This leads to the proposed protective HC among females from the risk of developing metabolic syndrome and CVD [8, 16, 21]. 
From our study, the total cholesterol level was predominantly correlated to the uric acid level and to MUAC compared to other anthropometry measurements. Raised cholesterol is reported to cause approximately 2.6 million deaths and 29.7 million disability adjusted life years. It is a risk factor for ischemic heart disease and stroke. High cholesterol levels could be occurred due to heredity i.e. familial hypercholesterolemia, excessive weight, exercise and/ or physical activity, age and sex, alcohol use and mental stress are some of determinants for. After approximately age 50 year old, women often have higher total cholesterol levels than men of the same age; whilst at pre-menopause women tend to have lower total cholesterol levels than men of the same age. Cholesterol is a fat-like substance needed to build various structures in the human body as well as to produce chemicals and hormones that are essentials for the body's function. However, excess amounts can be deposited at the vascular walls as the plaques thus might be decreasing the amount of blood flow to the organs [22, 24, 26].

Among males, we observed strong correspondence between each of the anthropometric measurement to the UA levels whilst similar pattern was only found between HC and UA among females. On the other hand, the uric acid levels in the current study were highly corresponded to the level of the total cholesterol in both genders. Where there is an imbalance between the breakdown of purines and the rate of uric acid excretion, hyperuricemia is produced. The uric acid in the blood is saturated at approximately 6.4 to $7 \mathrm{mg} / \mathrm{dL}$; where the urate is filtered through the glomerulus whilst reabsorbed, secreted and the reabsorbed again in the proximal tubule of the kidney. The increased in the serum urate level would increase the urate excretion $[11,18,19]$. Hyperuricemia have been associated to the increased the mortality rate in the patients of hypertension and stroke. It is reported that hyperuricemia is higher in the patients suffered from the metabolic syndrome. The underlying pathology may include the increased inflammatory pathway signaled by the raising of the level of c-reactive protein (CRP) and the IL-1 cytokine in the obesity which in turn would alter the structure of the kidney thus glomerular filtration function $[11,18,19]$.

Previous study reported that persons with obesity would have higher risk to develop the metabolic syndrome and CVD. In obesity the insulin resistance tend to easily occur and has been associated to the raised inflammatory cytokine levels i.e. TNF- $\alpha$ and leptin levels with low adiponectin levels [10, 22, 24]. These would subsequently facilitating the development of metabolic syndrome that increase the risk for suffering the diabetes mellitus type 2 (DM-2) and/or cardiovascular disease (CVD) [10, 22, 26]. Preventive and promotive medicine should be emphasized especially amongst the seemingly healthy youths to lowering the incidence of these diseases in the later life. These may include to having healthy diet for example foods rich in polyphenols i.e. berries and green tea $[27,28]$. Whilst practicing daily exercise and/or routine physical activity to balance the tendency of sedentary life style affected by too much of gadget use in this modern world would be beneficial even in the metabolically healthy obese persons to decrease the cardiovascular disease risks $[29,30]$.

\section{CONCLUSION}

The risk factor of CVDs could be found amongst the seemingly healthy young adults in our study. All anthropometry and biochemical markers studied were higher among males than among females. The total cholesterol and uric acid levels were significantly associated to all anthropometry studied among males, whilst among females strong correlation was only found between the hip circumference and the uric acid level.

\section{ACKNOWLEDGEMENTS}

Thank you to the Faculty of Medicine, Universitas Airlangga, Surabaya, Indonesia and The IIKBW, Kediri, Indonesia. This study received fundings from Universitas Airlangga.

\section{REFERENCES}

[1] Grundy SM., "Use of emerging lipoprotein risk factors in assessment of cardiovascular risk," JAMA, vol. 307, no. 23, pp. 2540-2542, 2012, doi: 10.1001/jama.2012.6896.

[2] Casas R., Castro-Barquero S., Estruch R., Sacanella E., "Nutrition and cardiovascular health," International Journal of Molecular Sciences., vol. 19, no. 12, p. 3988, 2018.

[3] Despres JP., "Body fat distribution and risk of cardiovascular disease," Circulation, vol. 126, no. 10, pp. 13011313. 2012.

[4] Hatma RD., "Lipid profiles among diverse ethnic groups in Indonesia," Acta Medica Indonesiana., vol. 43, no. 1, pp. 4-11, 2011.

[5] Cameron AJ, Romaniuk H., Orellana L., Dallongeville J., Dobson AJ, Drygas W., et al., "Combined influence of waist and hip circumference on risk of death in a large cohort of European and Australian adults," Journal American Heart Association., vol. 9, no. 13, pp. 1-14, 2020. 
[6] Sultana T., Karim MN, Ahmeed T., Hossain MI., "Assessment of undernutrition of Bangladeshi adults using anthropometry: can body mass index be replaced by mid-upper-arm-circumference?," Plos One, vol. 10, no. 4, pp. $1-8,2015$.

[7] Kihara S., Matzusawa Y., "Fat distribution and cardiovascular disease risk," Current Cardiovascular Risk Reports, vol. 9, no. 8, 2015.

[8] Bluher M., Laufs U., "New concepts for body shape-related cardiovascular risk: role of fat distribution and adipose tissue function,” European Heart Journal, vol. 40, no. 34, pp. 2856-2858, 2019.

[9] Caleyachetty R., Thomas GN, Toulis KA, Mohammed N., Gokhale KM, Balachandran K., Nirantharakumar K., "Metabolically healthy obese and incident cardiovascular disease events among 3.5 million men and women," Journal American College Cardiology., vol. 70, no 12, pp.1429-1437, 2017.

[10] Singh M., et al., "Anthropometric measures during infancy and childhood and the risk of developing cardiovascular disease or diabetes mellitus type 2 in later life: a systematic review," ICMR Advanced Centre for Evidence Based Child Health, PGIMER, 2015.

[11] Ali N., Perveen R., Rahman S., Mahmood S., Rahman S., Islam S., Haque T., Sumon AH., Kathak RR., Molla NH., Islam F., Mohanto NC., Nurunnabi SM., Ahmed S., Rahman M., "Prevalence of hyperuricemia and the relationship between uric acid level and obesity: A study on Bangladeshi adults," PloS One, vol. 13, no. 11, pp. 1-12, 2018.

[12] Scheuer Sh, Faerch K., Philipsen A., Jorgensen ME., Johansen NB., Carstensen B., Witte DR., Andersen I., Lauritzen T., andersen GS., "Abdominal fat distribution and cardiovascular risk in men and women with different levels of glucose tolerance," The Journal of Clinical Endocrinology \& Metabolism,” vol. 100, no. 9, pp. 3340-3347, 2015.

[13] Hastuti J., Kagawa M., Byrne NM., Hills AP., "Determination of new anthropometric cut-off values for obesity screening in Indonesian adults," Asia Pacific Journal Clinical Nutrition., vol. 26, no. 4, pp. 650-656, 2017.

[14] Bhattacharya A., Pal B., Mukherjee S., Roy SK., "Assessment of nutritional status using anthropometric variables by multivariate analysis," BMC Public Health, vol. 19, no. 1045, pp. 1-9, 2019.

[15] Sahakyan KR, Somers VK, Rodriguez-Escudero JP, Hodge DO, Carter RE, Sochor O., Coutinho T., jensen MD, Roger VL, Singh P., Lopez-Jimenez F., "Normal-weight central obesity: implications for total and cardiovascular mortality," Annals Internal Medicine, vol. 163, no. 11, pp. 827-835, 2015.

[16] Gazarova M., Galsneiderova M., Meciarova L., "Obesity diagnosis and mortality risk based on a body shape index (ABSI) and other indices and anthropometric parameters in university students," Roczniki Panstwowego Zakladu Higeny., vol. 70, no. 3, pp. 267-275, 2019.

[17] Yeboah J., McClelland RL, Polonsky TS, Burke GL, Sibley CT, O'Leary D, Carr JJ, Goff DC, Greenland P., Herrington DM., "Comparison of novel risk markers for improvement in cardiovascular risk assessment in intermediate-risk individuals," JAMA. vol. 308, no. 8, pp. 788-795, 2012.

[18] Tao M., Pi X., Ma X., Shi Y., Zhang Y., Gu H., Chi Y., Zhuang S., Liu N., "Relationship between serum uric acid and clustering of cardiovascular disease risk factors and renal disorders among Shanghai population: a multicentre and cross-sectional study," BMJ Open, vol. 9, no. 3, pp. 1-13, 2019.

[19] You L., Liu A., Wuyun G., Wu H., Wang P., "Prevalence of hyperuricemia and the relationship between serum uric acid and metabolic syndrome in the Asian Mongolian Area," Journal of Atherosclerosis and Thrombosis, vol. 21, no. 4, pp. 355-365, 2014.

[20] Lee YC, Chen CH, Khoo LP., "A pilot study of gender differences on anthropometric measurements in Singapore population," Advances in Physical Ergonomics and Human Factors, vol. 602, pp. 42-51, 2018.

[21] Cameron AJ, Magliano DJ, Shaw JE, et al., "The influence of hip circumference on the relationship between abdominal obesity and mortality," International Journal of Epidemiology, vol. 41, no. 2, pp. 484-494, 2012.

[22] Chang CJ, Jian DY, Lin MW, Zhao JZ, Ho LT, Juan CC. "Evidence in obese children: contribution of hyperlipidemia, obesity-inflammation, and insulin sensitivity," PLoS One., vol. 10, no. 5, pp. 1-12, 2015, doi: 10.1371/journal.pone.0125935.

[23] Gastaldelli A., Gaggini M., DeFronzo RA., "Role of adipose tissue insulin resistance in the natural history of type 2 diabetes: results from the San Antonio metabolism study,” Diabetes, vol. 66, no. 4, pp. 815-822, 2017.

[24] Turer CB, Brady TM, de Ferranti SD., "Obesity, hypertension, and dyslipidemia in childhood are key modifiable antecedents of adult cardiovascular disease: A call to action," Circulation, vol. 137, no. 12, pp. 1256-1259, 2018.

[25] Zhu Q., Wang XB, Yao Y., Ning CX, Chen XP, Luan FX, Zhao YL., "Association between anthropometric measures and cardiovascular disease (CVD) risk factors in Hainan centenarians: investigation based on the Centenarian's health study," BMC Cardiovascular Disorders, vol. 18, no. 1, p. 73, 2018.

[26] Islam J, Zaman MM, Haq SA, Ahmed S., Al Quadir Z., "Epidemiology of hypertension among Bangladeshi adults using the 2017 ACC/AHA Hypertension Clinical Practice Guidelines and Joint National Committee 7 Guidelines," Journal of Human Hypertension, vol. 32, no. 10, pp. 668-680, 2018.

[27] Huang H., Chen G., Liao D., Zhu Y., Xue X., "Effects of berries consumption on cardiovascular risk factors: a metaanalysis with trial sequential analysis of randomized controlled trials," Scientific Repots, vol. 6, no. 1, pp. 1-11, 2016.

[28] Basu A., Du M., Sanchez K., Leyva MJ, Betts NM, Blevins S, Wu M, Aston CE, Lyons TJ., "Green tea minimally affects biomarkers of inflammation in obese subjects with metabolic syndrome," Nutrition, vol. 29, no. 2, pp. 206213, 2011.

[29] World Health Organization. Global recommendations on physical activity for health. For 18-64 years old. 2011. [Online]. Avalable: https://www.who.int/dietphysicalactivity/factsheet_recommendations/en/.

[30] Moon S., Oh CM, Choi MK, Park YK, Chun S., Choi M., Yu JM, Yoo HJ., "The influence of physical activity on risk of cardiovascular disease in people who are obese but metabolically healthy," Plos One, vol. 12, no. 9, pp. 1$11,2017$. 